Article

\title{
Investigations of the Diurnal Variation of Vertical HCHO Profiles Based on MAX-DOAS Measurements in Beijing: Comparisons with OMI Vertical Column Data
}

\author{
Hanlim Lee ${ }^{1}$, Jaeyong Ryu ${ }^{2}$, Hitoshi Irie ${ }^{3}$, Seong-Ho Jang ${ }^{4, *}$, Junsung Park ${ }^{1}$, Wonei Choi ${ }^{1}$ \\ and Hyunkee Hong 1
}

1 Department of Spatial Information Engineering, Pukyong National University, Busan 608-737, Korea; E-Mails: hllee@pknu.ac.kr (H.L.); Junsung2ek@gmail.com (J.P.); cwyh3338@gmail.com (W.C.); brunhilt77@gmail.com (H.H.)

2 Department of Urban Environmental Engineering, Kyungnam University, Changwon-si, Gyeongsangnam-do 631-701, Korea; E-Mail: jaeyong03@gmail.com

3 Center for Environmental Remote Sensing, Chiba University, 1-33 Yayoicho, Inage-ku, Chiba 263-8522, Japan; E-Mail: hitoshi.irie@chiba-u.jp

4 Department of BioEnvironmental Energy, Pusan National University, Gyeongsangnam-do 627-706, Korea

* Author to whom correspondence should be addressed; E-Mail: jangsh@pusan.ac.kr; Tel.: +82-55-350-5435; Fax: +82-55-350-5439.

Academic Editor: Robert W. Talbot

Received: 22 July 2015 / Accepted: 17 November 2015 / Published: 20 November 2015

\begin{abstract}
An investigation into the diurnal characteristics of vertical formaldehyde (HCHO) profiles was conducted based on multi-axis differential optical absorption spectroscopy (MAX-DOAS) measurements in Beijing during the CAREBEIJING campaign, covering a month-long period through August and September 2006. Vertical $\mathrm{HCHO}$ profiles were retrieved based on a combined differential optical absorption spectroscopy (DOAS) technique and an optimal estimation method (OEM). The HCHO volume-mixing ratio (VMR) was found to be highest in the layer from the surface up to an altitude of $1 \mathrm{~km}$ and to decrease with altitude above this layer. In all retrieved profiles, $\mathrm{HCHO}$ was not detected in the layer from 3-4 km. Over the diurnal cycle, the HCHO VMR values were generally highest at 15:00 local time (LT) and were lower in the morning and late afternoon. The mean HCHO VMRs were 6.17, 1.82, and 0.80 ppbv for the $0-1,1-2$, and 2-3-km layers, respectively, at 15:00 LT, whereas they were 3.54 (4.79),
\end{abstract}


1.06 (1.43), and $0.46(0.63) \mathrm{ppbv}$ for the $0-1,1-2$, and 2-3-km layers, respectively, at 09:00 (17:00) LT. The HCHO VMRs reached their highest values at 15:00 LT on August 19, which were 17.71, 5.20, and $2.31 \mathrm{ppbv}$ for the $0-1,1-2$, and 2-3-km layers, respectively. This diurnal pattern implies that the photo-oxidation of volatile organic compounds (VOCs) was most active at 15:00 LT for several days during the campaign period. In a comparison of the derived HCHO VCDs with those obtained from the Ozone Monitoring Instrument (OMI) measurements, the HCHO vertical column density (VCD) values obtained from the OMI measurements tend to be smaller than those from the MAX-DOAS.

Keywords: HCHO profile; diurnal HCHO; MAX-DOAS; OMI; DOAS

\section{Introduction}

Formaldehyde (HCHO) is known to have adverse health effects such as damage to oral fibroblasts and epithelial cells [1]. Most HCHO is produced by the photo-oxidation of volatile organic compounds (VOCs) released from biogenic, anthropogenic, and pyrogenic sources [2]. VOCs are one of the causes of photochemical smog, while non-methane volatile organic compounds (NMVOCS) are a precursor of tropospheric ozone formation [3,4]. Background levels of $\mathrm{HCHO}$ are generally controlled by the amount of $\mathrm{CH}_{4}$ present in the troposphere, with the concentration of $\mathrm{CH}_{4}$ being relatively uniform due to its stability [5-7]. The lifetime of $\mathrm{HCHO}$ is only a few hours because it is broken down by photolysis (wavelengths smaller than $400 \mathrm{~nm}$ ) and chemical processes (reaction with hydroxyl radicals) [8].

To date, the analysis of HCHO has been based on in-situ samplers [9-12], tunable diode laser absorption spectrometer (TDLAS) [11,13,14], Hantzsch fluorometry [9,10,13], fourier transform infrared spectroscopy (FTIR) [9,11,13,15,16] and active and passive DOAS [9,11-13,16-19]. Hönninger et al. [20] introduced the multi-axis differential optical absorption spectroscopy (MAXDOAS) technique that utilizes scattered sunlight as a light source and retrieves the spatial distribution of various trace gases, including $\mathrm{HCHO}$. While this technique can directly retrieve a slant column density (SCD; a measure of the amount of the absorbing species in a cross-sectional area, integrated over the light path) of the target species, it is unable to yield vertical profiles of the species directly without detailed radiative transfer information. However, the MAX-DOAS technique has recently been employed to retrieve information regarding the vertical distribution of HCHO. Previous studies [1,21-23] retrieved vertical profiles of trace gases combining MAX-DOAS measurements with the output from radiative transfer models (RTMs). These studies derived both the vertical column amount of $\mathrm{HCHO}$ and its vertical distribution.

Nevertheless, to understand the diurnal photo-oxidation patterns of VOCs and the temporal characteristics of vertical HCHO dispersions, there remains a need for further investigation of the diurnal characteristics of vertical $\mathrm{HCHO}$ distributions. We therefore present an investigation into the diurnal characteristics of vertical HCHO profiles, based on MAX-DOAS measurements in Beijing during the CAREBEIJING campaign over a month-long period through August and September 2006. 
$\mathrm{HCHO}$ vertical column densities retrieved from the MAX-DOAS measurements are also compared, for this time period, with data from the Ozone Monitoring Instrument (OMI).

\section{Measurements}

The ultraviolet (UV) mini MAX-DOAS system used in this work has been utilized in a previous study conducted by Lee et al. [24,25]. The sequential MAX-DOAS system comprises a light-collecting unit and a small spectrograph, both housed in an aluminum box. The entrance optic is connected to a quartz fiber, which includes a quartz lens with a focal length of $40 \mathrm{~mm}$ and a diameter of $20 \mathrm{~mm}$. The miniature spectrograph (USB2000; Ocean optics, Dunedin, Florida, USA) covers a spectral range of 289-431 nm at a spectral resolution of $0.7 \mathrm{~nm}$ (FWHM), and employs a charge-coupled device (CCD) detector (Sony ILX511, 2048 pixels). The intensity of visible light (wavelength $>400 \mathrm{~nm}$ ) entering the spectrograph is reduced by the placement of a UG5 filter in front of the quartz lens. A Peltier element is attached to the spectrograph plate to maintain a constant low temperature $\left(10 \pm 0.5^{\circ} \mathrm{C}\right)$ and minimize the dark current signal to the CCD.
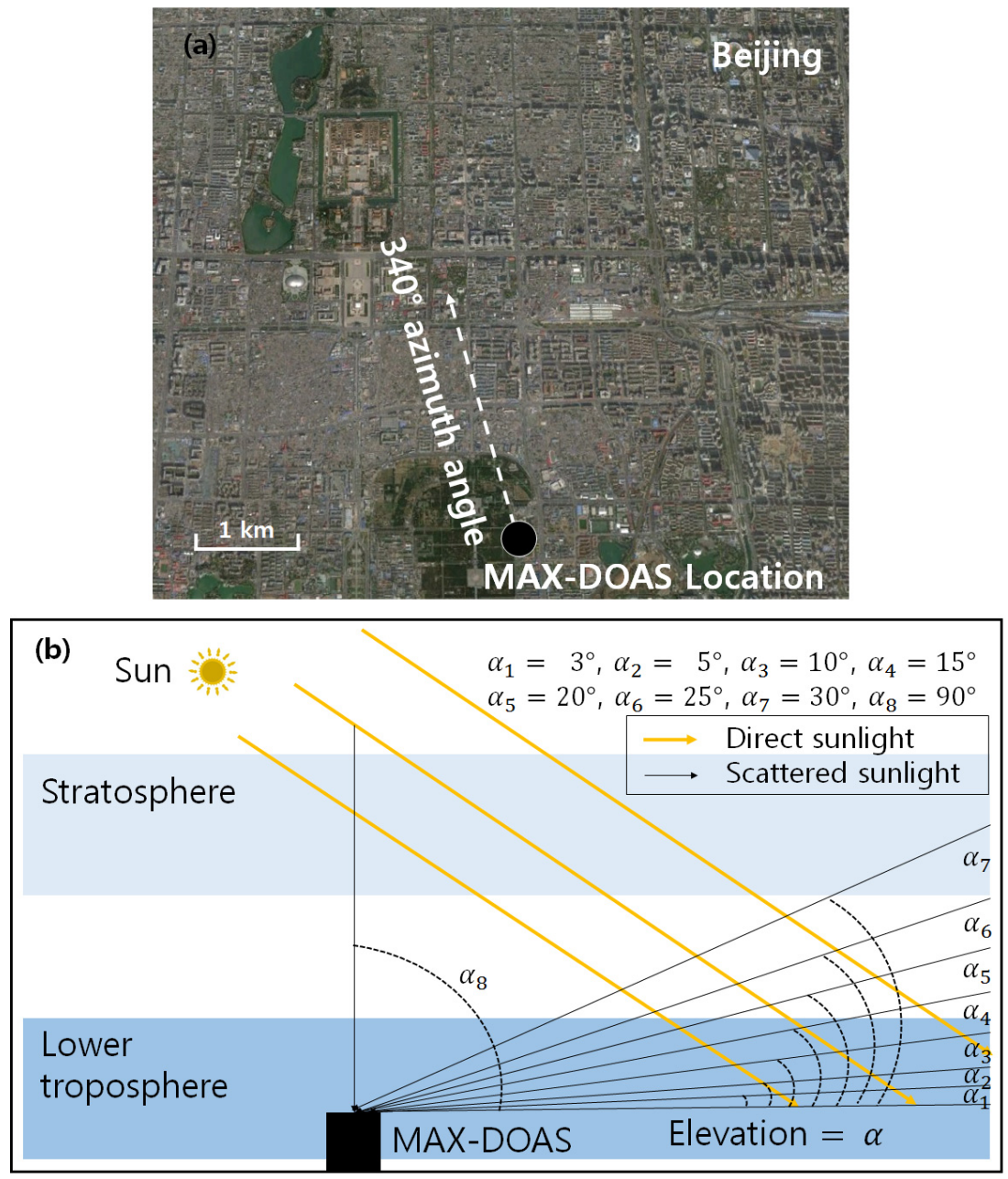

Figure 1. (a) Location map of the measurement site in Beijing. The direction of the MAX-DOAS measurement is indicated by the dashed arrow. (b) The MAX-DOAS observation geometry used during the CAREBEIJING campaign. 
MAX-DOAS measurements were collected between 09:00 and 17:00 local time (LT) (corresponding to $47^{\circ}$ and $75^{\circ}$ solar zenith angle) on the rooftop of the Mathematics Building $\left(39.59^{\circ} \mathrm{N}, 116.18^{\circ} \mathrm{E} ; 55 \mathrm{~m}\right.$ above ground level) on the campus of Beijing University. The viewing azimuth angle of the MAX-DOAS was $340^{\circ}$, pointing toward the north of Beijing (Figure 1a). The aluminum box containing the MAX-DOAS system was connected to a stepper motor, and sequential recordings of scattered sunlight signals were made at elevation angles (EAs) of $3^{\circ}, 5^{\circ}, 10^{\circ}, 15^{\circ}, 20^{\circ}$, and $90^{\circ}$ above the horizon during the measurement period (Figure 1b). Elevation angles lower than $3^{\circ}$ were not used to avoid surface obstacles on light paths along the line of sight. The MAX-DOAS measurements were performed every $2 \mathrm{~h}$ in an automated measurement loop, with each loop taking 9-15 min to scan the six EAs. The measured MAX-DOAS spectra were analyzed to quantify HCHO according to its specific structured absorption features in the UV wavelength range.

\section{MAX-DOAS Data Analysis}

\subsection{Retrieval of $\mathrm{HCHO}$ and $\mathrm{O}_{4} \mathrm{SCDS}$}

The recorded MAX-DOAS data were analyzed to derive HCHO SCDs using QDOAS software [21] based on the DOAS technique [26]. Dark current and offset signals from the MAX-DOAS CCD detector were recorded before and after daily measurements and then removed from the scattered sunlight spectra. The wavelengths of the spectra recorded by the MAX-DOAS system were calibrated by fitting the raw spectra to a solar reference spectrum [27]. The DOAS fitting was carried out over several wavelength intervals with the absorption cross-sections listed in Table 1. The spectral interval from 335 to $357 \mathrm{~nm}$ was found to have the smallest fitting errors, the mean value of which was about $5 \%$ of the retrieved HCHO SCDs. In the present study, the HCHO SCDs were therefore derived in the spectral interval 335-357 nm, where three strong $\mathrm{HCHO}$ absorption bands exist. A spectrum recorded at around 12:00 LT on September 9 was used as the Fraunhofer reference spectrum (FRS). On this day, the skies were free of clouds and visibility was good. The FRS and Ring spectra, as well as the absorption cross-sections of $\mathrm{HCHO}, \mathrm{O}_{3}, \mathrm{O}_{4}$, and $\mathrm{NO}_{2}$ were simultaneously fitted to the measurement spectra using a nonlinear least-squares method [26,28] within the QDOAS software. The HCHO absorption cross-section [29], which is also used in the OMI HCHO operational algorithm [30], was used in this present study. The $\mathrm{HCHO}$ cross-section [29] may contain the uncertainty [31]. The BrO absorption cross-section was excluded in the spectral fitting routine due to either no or negligible $\mathrm{BrO}$ absorption in the measured spectra. Table 1 describes the parameters used for the spectral analysis using the DOAS method. All reference absorption cross-section spectra were convolved with the slit function to match the spectral resolution of the MAX-DOAS system used in this study. The Ring effect describes the so-called "filling-in" of solar Fraunhofer lines in the spectra of scattered light compared with direct sunlight observations and is caused by rotational Raman scattering by atmospheric molecules [32]. Ring spectra [32], used to account for rotational Raman scattering effects, were calculated from the FRS using DOASIS software [33]. $\mathrm{NO}_{2}$ and $\mathrm{O}_{3}$ spectra were $\mathrm{I}_{0}$-corrected using QDOAS software. 
Table 1. Parameter settings used for the spectral analysis using the DOAS method.

\begin{tabular}{cccc}
\hline Target Species & $\begin{array}{c}\text { Wavelength Range } \\
(\mathbf{n m})\end{array}$ & $\begin{array}{c}\text { Polynomial } \\
\text { Order }\end{array}$ & $\begin{array}{c}\text { Absorption Cross-Sections Included in } \\
\text { the Spectral Fitting Routine }\end{array}$ \\
\hline $\mathrm{HCHO}$ & $335-357$ & $3 \mathrm{rd}$ & $\mathrm{HCHO}[29], \mathrm{O}_{3}[34], \mathrm{O}_{4}[35], \mathrm{NO}_{2}[36]$, \\
$\mathrm{O}_{4}$ & $338-367$ & & Ring spectra \\
\hline
\end{tabular}

Figure 2 shows the temporal variations of HCHO SCDs at each EA, and excludes data from cloudy and rainy days. The HCHO SCD values ranged from $-5.11 \times 10^{16}$ to $2.30 \times 10^{17}$ molecules cm ${ }^{-2}$. There are some negative $\mathrm{O}_{4}$ and HCHO SCDs as shown in Figure 2 due to the optical density fitting when the SCD of a trace gas (which is absorbed in the FRS) is smaller than that in other spectra that are to be analyzed. The high values observed at low EAs $\left(3^{\circ}\right.$ and $\left.5^{\circ}\right)$ suggest higher concentrations of $\mathrm{HCHO}$ near the surface than at higher altitudes. HCHO differential slant column densities (DSCDs) at other EAs were then obtained by subtracting the SCD at each EA from the SCD at $90^{\circ}$ within the same measurement loop [37].

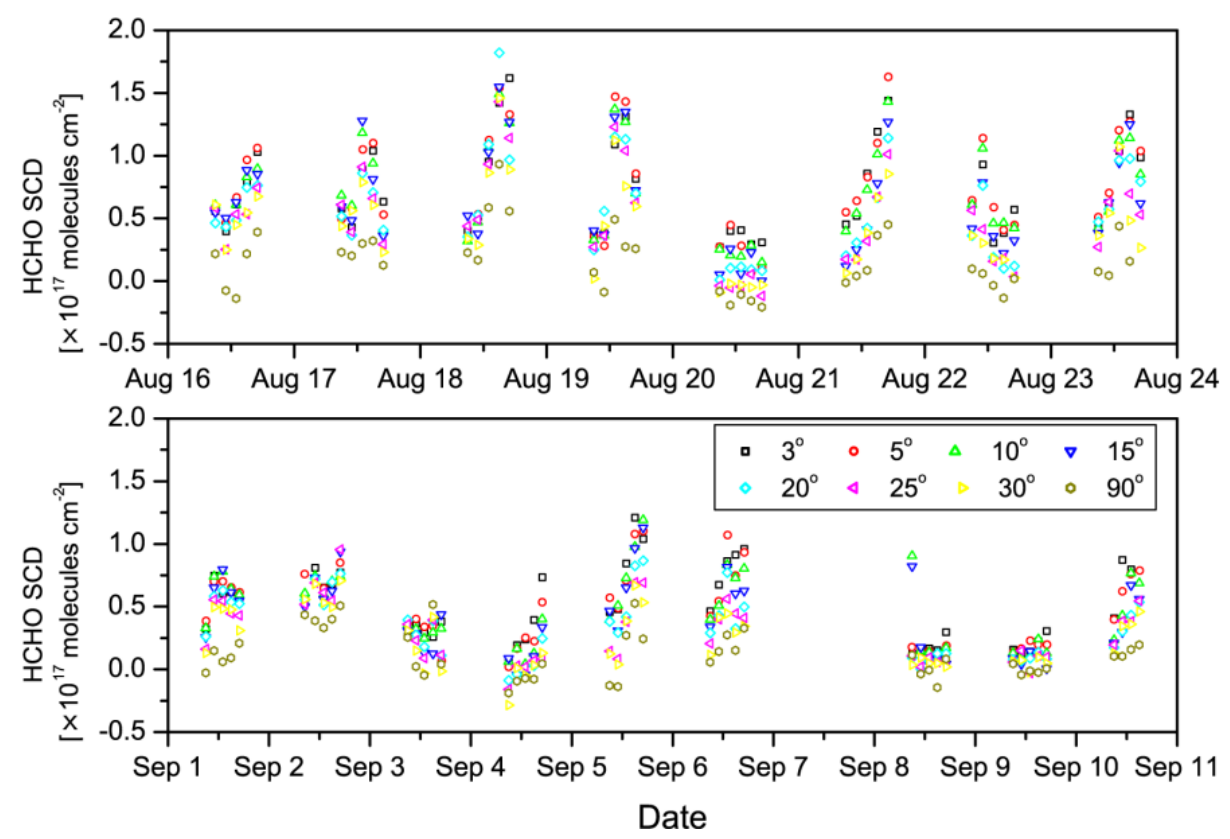

Figure 2. Temporal variations in $\mathrm{HCHO} S C D$ values obtained at $\mathrm{EA}=3^{\circ}, 5^{\circ}, 10^{\circ}, 15^{\circ}$, $20^{\circ}, 25^{\circ}, 30^{\circ}$, and $90^{\circ}$.

The recorded MAX-DOAS data were also analyzed to derive $\mathrm{O}_{4} \mathrm{SCDs}$, which can be used to simulate vertical distributions of aerosol extinction coefficients (AECs) needed to obtain the HCHO volume mixing ratios (VMRs). $\mathrm{O}_{4}, \mathrm{NO}_{2}, \mathrm{O}_{3}, \mathrm{HCHO}, \mathrm{FRS}$, and the ring spectrum were simultaneously fitted to measurement spectra in the wavelength interval $338-367 \mathrm{~nm}$, using the same nonlinear least squares method used for the HCHO SCD retrieval. This wavelength interval was chosen to provide the vertical distribution information of AECs at $352 \mathrm{~nm}$, which is within the wavelength interval used for the $\mathrm{HCHO}$ vertical profile retrieval. Figure 3 shows an example of deconvolution of the DOAS spectrum in evaluating $\mathrm{HCHO}$ and $\mathrm{O} 4$ slant column densities at 15:00 LT on 17 August 2006. 

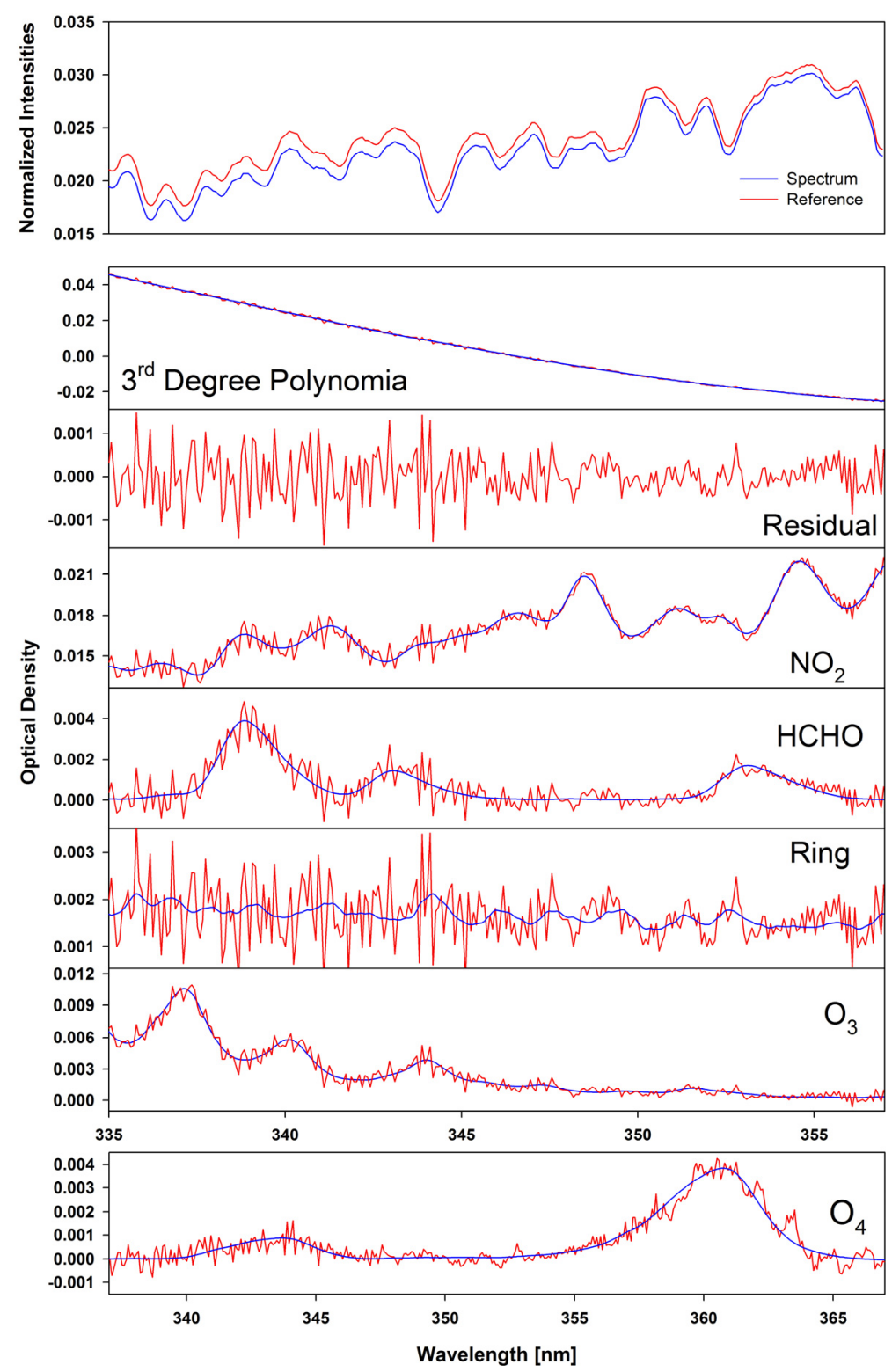

Figure 3. Example of deconvolution of the DOAS spectrum in evaluating $\mathrm{HCHO}$ and $\mathrm{O}_{4}$ slant column densities. Blue lines represent the absorption signal and red lines represent the sum of the absorption signal and the fit residual. The residual is small compared with $\mathrm{HCHO}$ and $\mathrm{O}_{4}$ absorption. The example spectrum was obtained at 15:00 on 17 August 2006.

The $\mathrm{O}_{4}$ absorption cross-section was obtained from Hermans et al. [35]. Wagner et al. [38] and Clémer et al. [39] suggested a need for a correction factor of 1.25 for the $\mathrm{O}_{4}$ absorption cross-section. Recently, Irie et al. [40] reported that adopting an elevation-angle-dependent factor for the $\mathrm{O}_{4}$ absorption cross-section correction effectively reduces the difference between the measured and simulated $\mathrm{O}_{4}$ DSCDs at high EAs. However, we multiplied the $\mathrm{O}_{4}$ absorption cross-section by a factor of 1.25 prior to the fitting procedure as done in previous studies [24,37,41] since our aerosol profile retrieval algorithm has not been updated to adopt an elevation-angle-dependent correction factor suggested by Irie et al. [40]. Figure 4 shows the temporal variations of $\mathrm{O}_{4} \mathrm{SCDs}$ at each EA. The $\mathrm{O}_{4}$ SCD values range from $-5.01 \times 10^{42}$ to $6.50 \times 10^{43}$ molecules ${ }^{2} \cdot \mathrm{cm}^{-5}$. The $\mathrm{O}_{4}$ DSCDs at each EA were calculated by subtracting the SCD at each EA from the SCD at $90^{\circ}$ within the same measurement loop. 

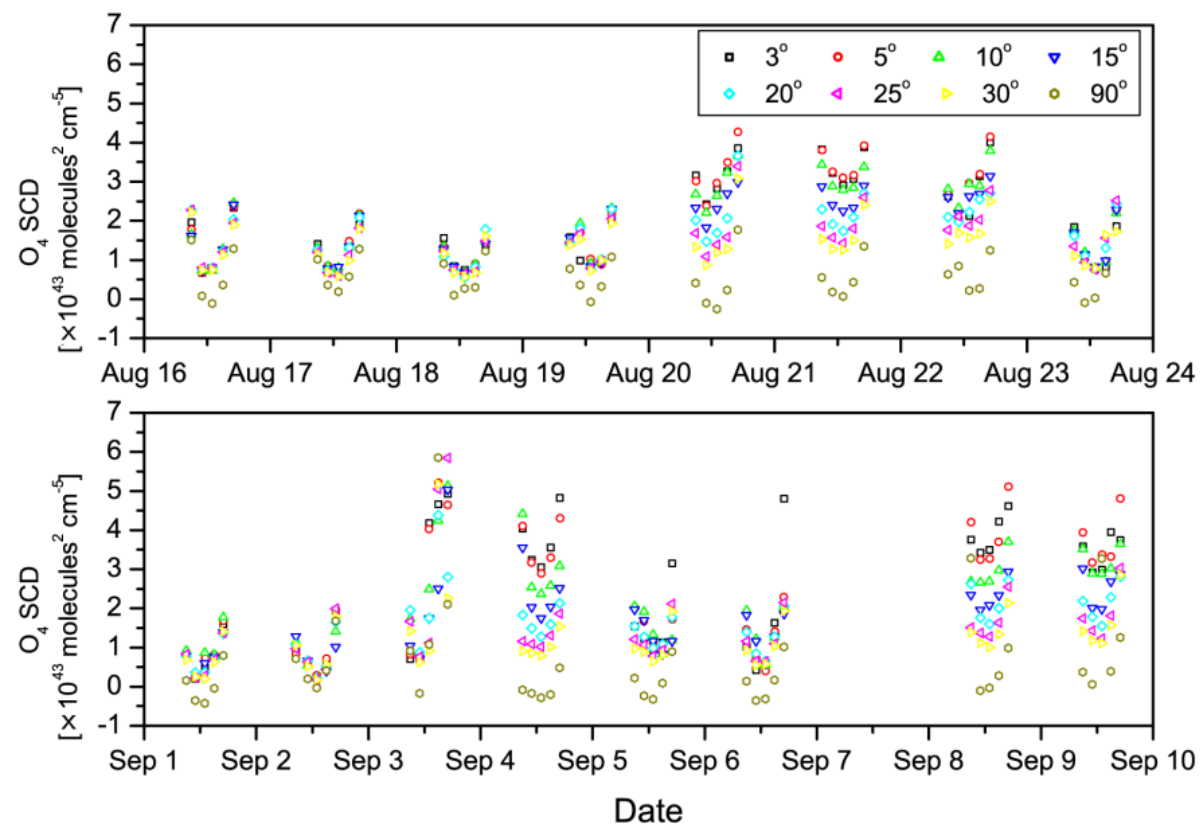

Figure 4. Temporal variations in $\mathrm{O}_{4} \mathrm{SCD}$ values obtained at $\mathrm{EA}=3^{\circ}, 5^{\circ}, 10^{\circ}, 15^{\circ}, 20^{\circ}$, $25^{\circ}, 30^{\circ}$, and $90^{\circ}$.

\subsection{Derivation of Vertical HCHO Profiles}

To retrieve vertical distributions of HCHO VMRs, AEC vertical distributions were initially derived using $\mathrm{O}_{4}$ DSCDs. The aerosol retrieval algorithm using MAX-DOAS data is based on a relationship in which $\mathrm{O}_{4}$ SCD decreases as aerosol load increases, as discussed by Wagner et al. [42]. An aerosol profile and aerosol optical depth (AOD) can be determined by simultaneously fitting the simulated $\mathrm{O}_{4}$ DSCDs to the $\mathrm{O}_{4}$ DSCDs measured by MAX-DOAS, based on the nonlinear inversion of the optimal estimation method [43]. The $\mathrm{O}_{4}$ DSCDs are calculated using a radiative transfer model (RTM), which requires information such as measurement geometries and aerosol optical properties, including AEC profiles. We used a lookup table (LUT) containing sets of $\mathrm{O}_{4}$ DSCDs obtained from the LIBrary for RADiative TRAnsfer (LIBRADTRAN) for the following: AOD, the shape parameters of the vertical distributions $\left(F_{1}, F_{2}, F_{3}\right.$, and $\left.F_{4}\right)$, the solar zenith angle (SZA), the relative azimuth angle (RAA, the azimuth angle between the telescope and the sun), and EA. Mean aerosol extinctions in the layers at altitudes of $0-1 \quad 1-2,2-3$, and 3-4 $\mathrm{km}$ are described as $\mathrm{AODF}_{1}, \quad \operatorname{AOD}\left(1-\mathrm{F}_{1}\right) \mathrm{F}_{2}$, $\operatorname{AOD}\left(1-\mathrm{F}_{1}\right)\left(1-\mathrm{F}_{2}\right) \mathrm{F}_{3}$, and $\operatorname{AOD}\left(1-\mathrm{F}_{1}\right)\left(1-\mathrm{F}_{2}\right)\left(1-\mathrm{F}_{3}\right) \mathrm{F}_{4}$, respectively. For $\mathrm{O}_{4} \mathrm{DSCD}$ simulations using the RTM, we assumed a single-scattering albedo $\mathrm{s}=0.93$, an asymmetry parameter $\mathrm{g}=0.69$ (from the Henyey-Greenstein approximation), and a surface albedo $\mathrm{a}=0.10$. The sensitivities of the retrieved AECs to changing these parameters (g, s, and a) by \pm 0.05 were estimated to be less than $8 \%, 1 \%$, and $2 \%$, respectively. A priori vertical AEC profiles were used to perform the least squares fit between the measured and simulated $\mathrm{O}_{4} \mathrm{DSCD}$ at several EAs. The $a$ priori values ( \pm errors) were AOD $=0.4 \pm 4.00$, $\mathrm{F}_{1}=0.70 \pm 0.05, \mathrm{~F}_{2}=0.60 \pm 0.03, \mathrm{~F}_{3}=0.60 \pm 0.03$, and $\mathrm{F}_{4}=0.60 \pm 0.03$. The a priori value of AOD was obtained from the collocated sunphotometer measurement data during the campaign. A priori values of F1, F2, F3, and F4 were adopted from a previous study [44]. The overall errors, calculated as the root-sum-squares of these errors, were $0.03(12 \%), 0.02 \mathrm{~km}^{-1}(18 \%)$, and $0.01 \mathrm{~km}^{-1}$ (44\%) for 
optical depth $\tau$ and aerosol extinction coefficients in the $0-1$ and 1-2-km layers, respectively [37]. The resulting degrees of freedom for signal [43] ranged from 1.1 to 2.8 for the measurement period.

The retrieval of the vertical $\mathrm{HCHO}$ distribution was carried out using a similar procedure to the retrieval of the AEC vertical distribution described above. HCHO vertical profiles were also determined by simultaneously fitting the derived HCHO DSCDs to the HCHO at all EAs measured by MAX-DOAS. The retrieved AEC vertical distributions with $\mathrm{HCHO}$ vertical shape variables were used as inputs to simulate HCHO DSCDs using the RTM. An LUT containing sets of HCHO DSCDs was obtained using the same RTM variables as for the AEC retrieval. Mean HCHO mixing ratios in the $0-1,1-2,2-3$, and 3-4-km layers are described as $\operatorname{VCDF}_{1}, \operatorname{VCD}\left(1-\mathrm{F}_{1}\right) \mathrm{F} 2, \mathrm{VCD}\left(1-\mathrm{F}_{1}\right)\left(1-\mathrm{F}_{2}\right) \mathrm{F}_{3}$, and $\operatorname{VCD}\left(1-\mathrm{F}_{1}\right)\left(1-\mathrm{F}_{2}\right)\left(1-\mathrm{F}_{3}\right) \mathrm{F}_{4}$, respectively, where $\mathrm{VCD}$ represents the vertical column density. For the factors F1, F2, and F3 determining the profile shape, we use the same a priori values as for the aerosol retrievals. Thus, a priori values used for $\mathrm{HCHO}$ retrieval were $\mathrm{VCD}=5 \times 10^{16}$ molecules $\mathrm{cm}^{-2}$, $\mathrm{F}_{1}=0.70 \pm 0.05, \mathrm{~F}_{2}=0.60 \pm 0.03, \mathrm{~F}_{3}=0.60 \pm 0.03$, and $\mathrm{F}_{4}=0.60 \pm 0.03$. The a priori value for $\mathrm{VCD}$ was obtained from the OMI data.

The errors of the retrieved state vector were calculated by the retrieval covariance matrix according to the optimal estimation method [43]:

$$
\hat{S}=\left(K^{T} S_{\varepsilon}^{-1} K+S_{a}^{-1}\right)
$$

where $\mathrm{K}, \mathrm{S}_{\varepsilon}$, and $\mathrm{S}_{\mathrm{a}}$ denote the weighting function matrix, the measurement error covariance matrix, and the a priori covariance matrix, respectively. The overall errors, calculated as the root-sum-squares of these errors, were $21 \%, 32 \%$, and $42 \%$ for VCD, VMR at the $0-1-\mathrm{km}$ layer, and VMR at the 1-2-km layer, respectively. The DOAS fitting errors were categorized as the random error and were also included in the estimated overall errors. Detailed descriptions of the error budget can be found in a previous study [41]. The errors in aerosol extinction coefficients at altitudes higher than $2 \mathrm{~km}$ were $\sim 80 \%$ because the sensitivity of the measurements decreases with increasing tropospheric altitude $[44,45]$.

\section{Results and Discussion}

As discussed in Section 3.2, the information from the AEC profiles was used as an input for simulating HCHO DSCDs in the retrieval of the HCHO profiles. Figure 5 shows the mean diurnal variations in the vertical profiles of the aerosol extinction coefficients over the entire measurement period. Enhanced aerosol extinction coefficients were observed around 12:00 LT. The highest AEC values were observed at 13:00 LT, and were $0.46,0.11$, and $0.04 \mathrm{~km}^{-1}$ for the $0-1,1-2$, and $2-3-\mathrm{km}$ layers, respectively. The lowest AEC values, observed at 17:00 LT, were $0.24,0.06$, and $0.02 \mathrm{~km}^{-1}$ for the $0-1,1-2$, and $2-3-\mathrm{km}$ layers, respectively.

Figure 6 shows the mean diurnal variations in the vertical profiles of HCHO VMRs over the measurement period. HCHO concentrations were low at 09:00 and 17:00 LT, and were higher at 13:00 and 15:00 LT. The HCHO VMRs were 3.54, 1.06, and $0.46 \mathrm{ppbv}$ for the $0-1,1-2$, and 2-3-km layers, respectively, at 09:00 LT; they were $6.17,1.82$, and $0.80 \mathrm{ppbv}$ for the $0-1,1-2$, and 2-3-km layers, respectively, at 15:00 LT. The increased $\mathrm{HCHO}$ at 15:00 LT implies that photo-oxidation of VOCs was very rapid due to the peak solar irradiance at this point in the day. The magnitude of the HCHO variation was greater near the surface than at altitudes higher than the $0-1-\mathrm{km}$ layer, as shown in Figure 6. 


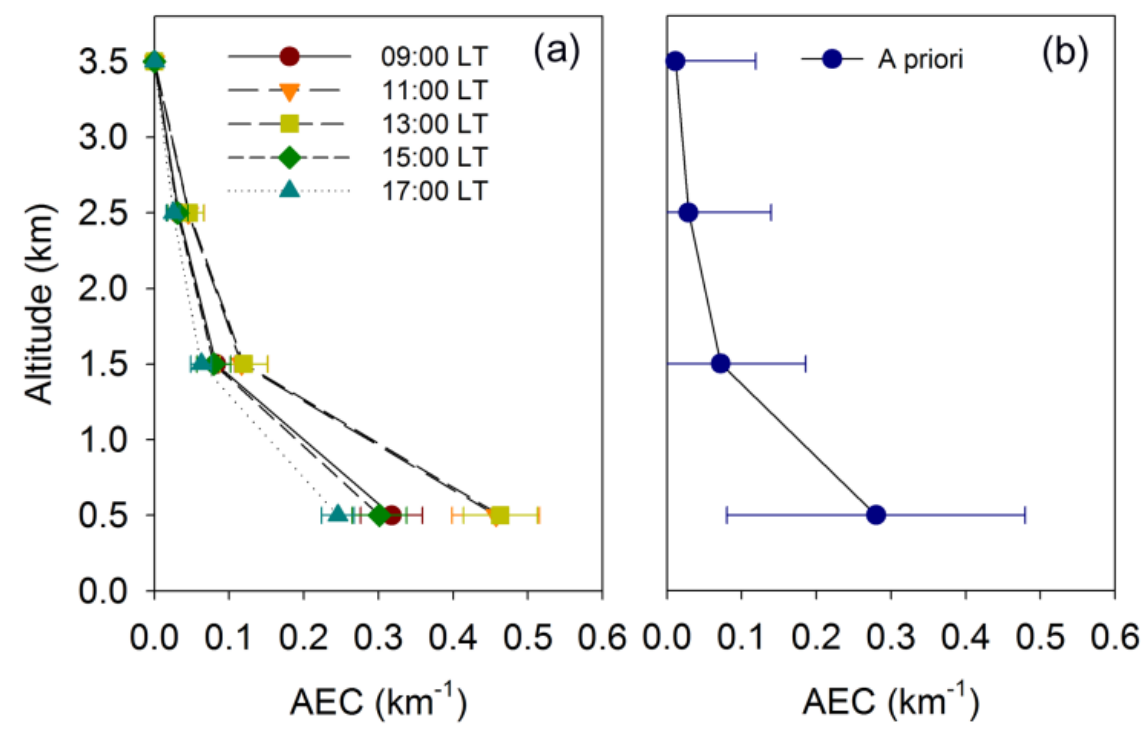

Figure 5. (a) Mean values of the AEC $(353 \mathrm{~nm})$ vertical profile with error bars obtained from MAX-DOAS measurements at different times of the day during the CAREBEIJING campaign. Error bars represent the mean errors estimated from the retrieval covariance matrix. (b) A priori AEC (353 nm) vertical distribution used in the present study.
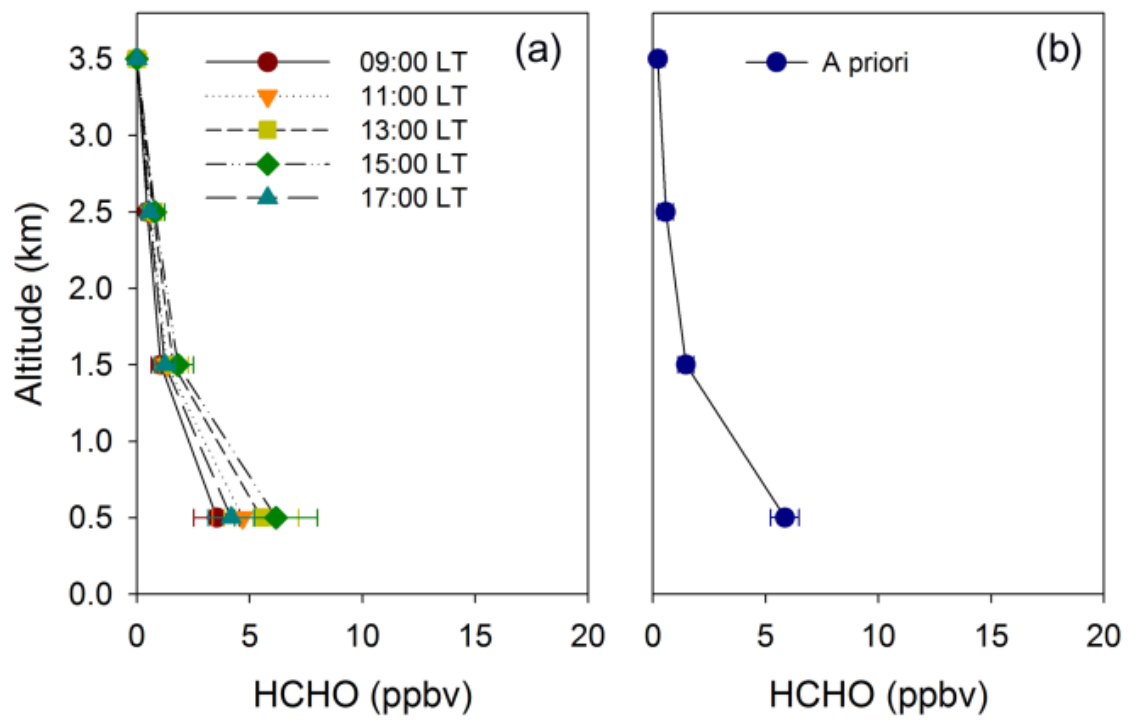

Figure 6. (a) Mean values of the $\mathrm{HCHO}$ vertical profile with error bars obtained from MAX-DOAS measurements at different times of the day during the CAREBEIJING campaign. Error bars represent the standard deviations. (b) A priori $\mathrm{HCHO}$ vertical distribution used in the present study.

Figures 7 and 8 show the daily diurnal variations of the vertical HCHO profiles during the measurement period. No HCHO vertical profiles were retrieved at the time when the corresponding aerosol vertical profiles were not available due to high AOD values larger than 5 , the largest value in the LUTs in Figures 7 and 8. The lowest HCHO VCDs were observed on September 9, when the HCHO VMRs ranged from 0.46 to $1.19,0.13$ to 0.37 , and 0.06 to $0.16 \mathrm{ppbv}$ for the $0-1,1-2$, and 2-3-km layers, respectively. The highest HCHO VCDs were observed on August 19. On this day, the 
HCHO VMRs reached their lowest values at 09:00 LT, which were 4.23, 1.20, and 0.54 ppbv for the 0-1, 1-2, and 2-3-km layers, respectively. The HCHO VMRs peaked at 15:00 LT, reaching values of $17.71,5.20$, and $2.31 \mathrm{ppbv}$ for the $0-1,1-2$, and 2-3-km layers, respectively. In all cases, the HCHO VMRs decreased with altitude. This result suggests that the majority of the VOCs were converted into $\mathrm{HCHO}$ in the $0-1-\mathrm{km}$ layer.
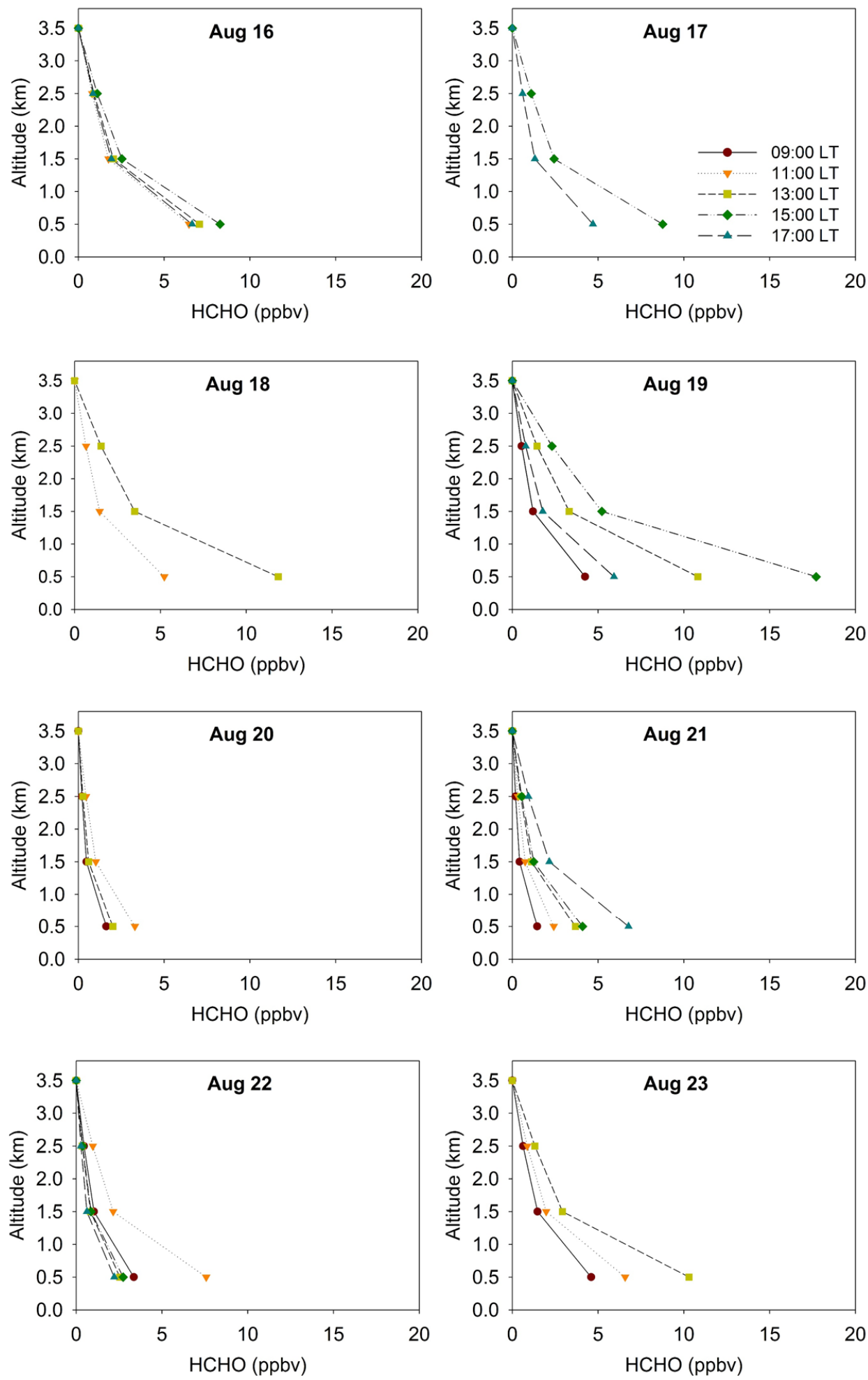

Figure 7. Daily diurnal variations in the vertical HCHO profiles obtained from the MAX-DOAS measurements in August during the CAREBEIJING campaign. 

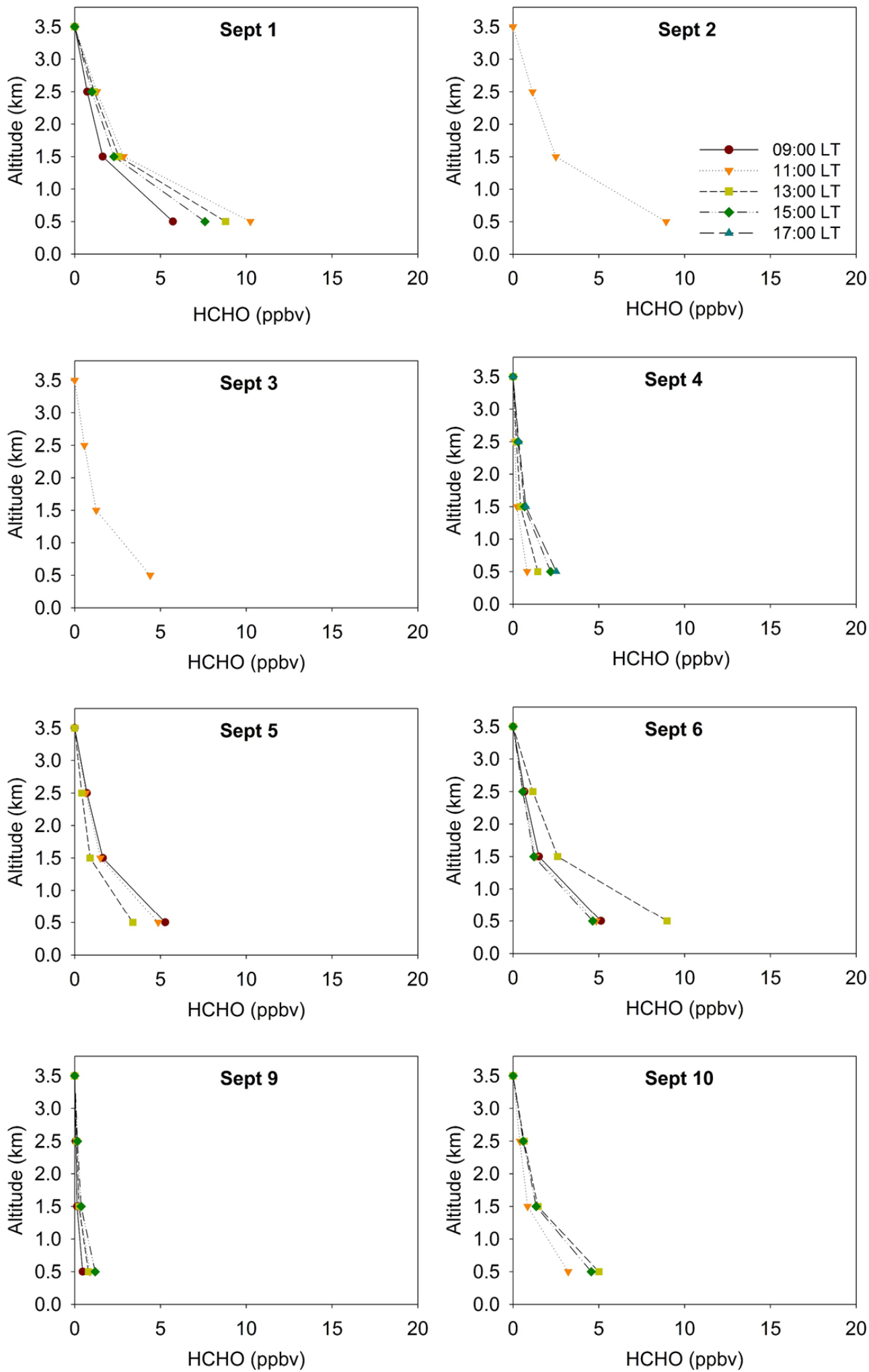

Figure 8. Daily diurnal variations of the vertical $\mathrm{HCHO}$ profiles obtained from the MAX-DOAS measurements in September during the CAREBEIJING campaign. 

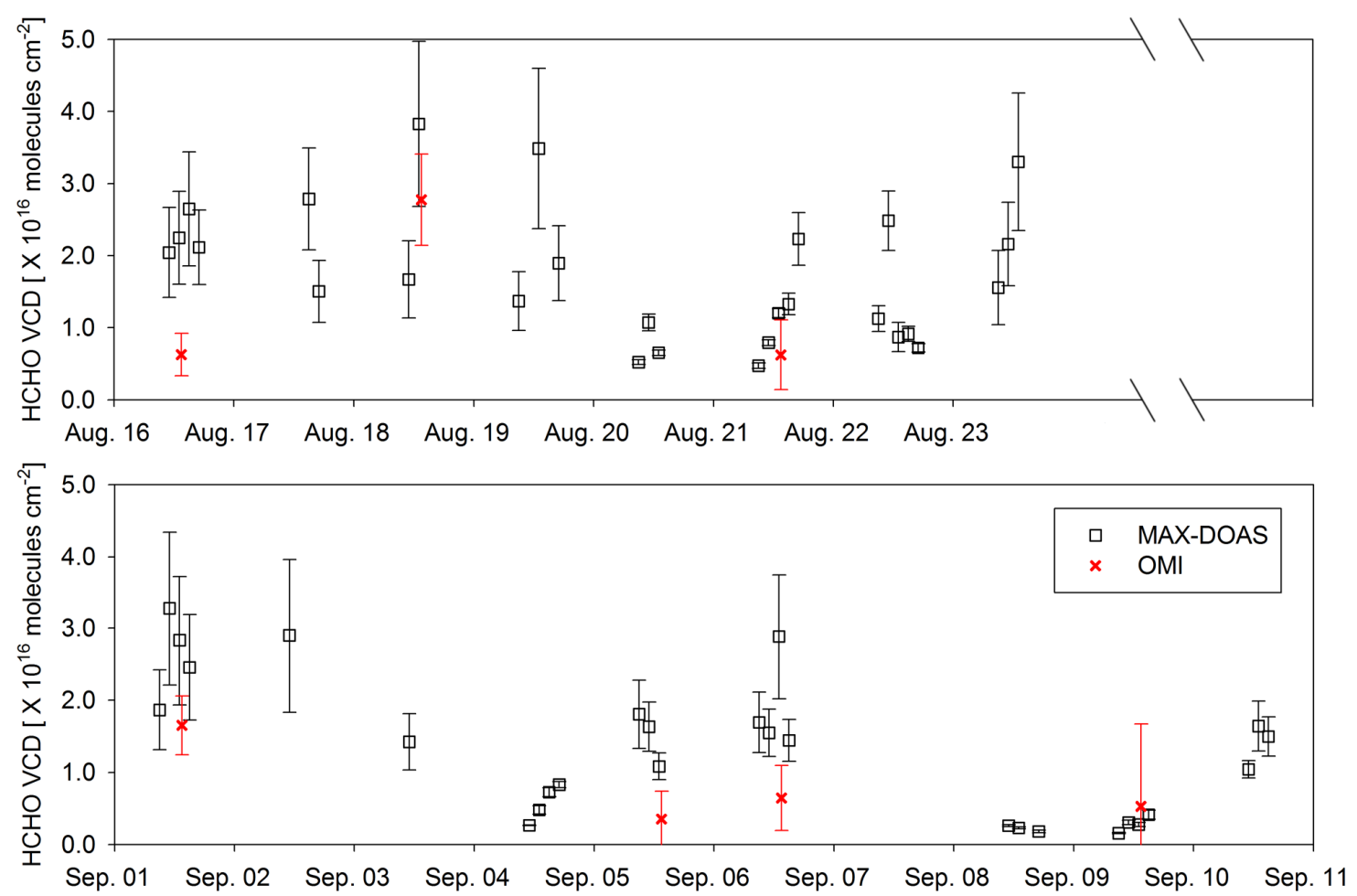

Figure 9. Temporal variations of HCHO VCDs obtained from the MAX-DOAS and OMI measurements during the CAREBEIJING campaign. The error bars (MAX-DOAS) represent the mean errors estimated from the retrieval covariance matrix whereas the error bars (OMI) represent the retrieval uncertainties.

We compared the HCHO VCDs retrieved from the MAX-DOAS measurements with the HCHO VCD data obtained from the OMI measurements (OMI Formaldehyde Level2G Global binned data; OMHCHOG). The OMI data were supplied by the NASA Goddard Earth Sciences Data and Information Service Center (http://disc.sci.gsfc.nasa.gov/Aura/data-holdings/OMI) [30]. Figure 9 shows the temporal variations in HCHO VCDs retrieved from the MAX-DOAS measurements, and those obtained from the OMI measurements in Beijing. In Figure 9, the error bars of the MAX-DOAS VCDs were calculated using Equation (1). The MAX-DOAS HCHO VCDs, which were temporally collocated within \pm 45 min of the OMI overpass time at 13:45 LT, are plotted in Figures 9 and 10. The OMI data were plotted in Figures 9 and 10 when the OMI data were available on the MAX-DOAS measurement location and the collocated MAX-DOAS data also existed. Data screening was done for optically thick cloud conditions by the maximum AOD value of 5 in the LUTs, which is thought to exclude large optical depth cases mostly due to optically thick clouds. The mean HCHO VCD value retrieved from the MAX-DOAS measurement was $1.79 \times 10^{16}$ molecules $\cdot \mathrm{cm}^{-2}$, which is higher than $1.07 \times 10^{16}$ molecules $\cdot \mathrm{cm}^{-2}$, the mean HCHO VCD value obtained from the OMI measurement. The maximum $\mathrm{HCHO}$ VCD retrieved from the MAX-DOAS measurements on August 18 was $3.83 \times 10^{16}$ molecules $\cdot \mathrm{cm}^{-2}$; the equivalent maximum from the OMI data was $2.78 \times 10^{16}$ molecules $\cdot \mathrm{cm}^{-2}$. The minimum HCHO VCD value retrieved from the MAX-DOAS measurements was $2.32 \times 10^{15}$ molecules $\cdot \mathrm{cm}^{-2}$ on September 8 , while that of the OMI data was $3.56 \times 10^{15}$ molecules $\cdot \mathrm{cm}^{-2}$ on September 5. In Figure 9, the HCHO VCD values retrieved using the MAX-DOAS data are plotted against the OMI data. The coefficient of determination (R2) is 0.62 , and the slope of regression 
equation is 0.56 . A possible reason for this tendency could be a weak sensitivity of the UV satellite sensor to $\mathrm{HCHO}$, which mostly exists near the surface. The uncertainties in the air mass factor (AMF) for the OMI HCHO retrieval due to the uncertainties related to the aerosol information and HCHO vertical profile shape could also lead to the difference between the HCHO VCDs obtained from those two methods. The uncertainty in AMF due to assumptions of the vertical profile shape is known to be up to $20 \%$, which leads to $20 \%$ uncertainty in the HCHO VCDs [46]. Moreover, the satellite averages over the whole pixel area while the MAX-DOAS is probably more sensitive to a smaller coverage.

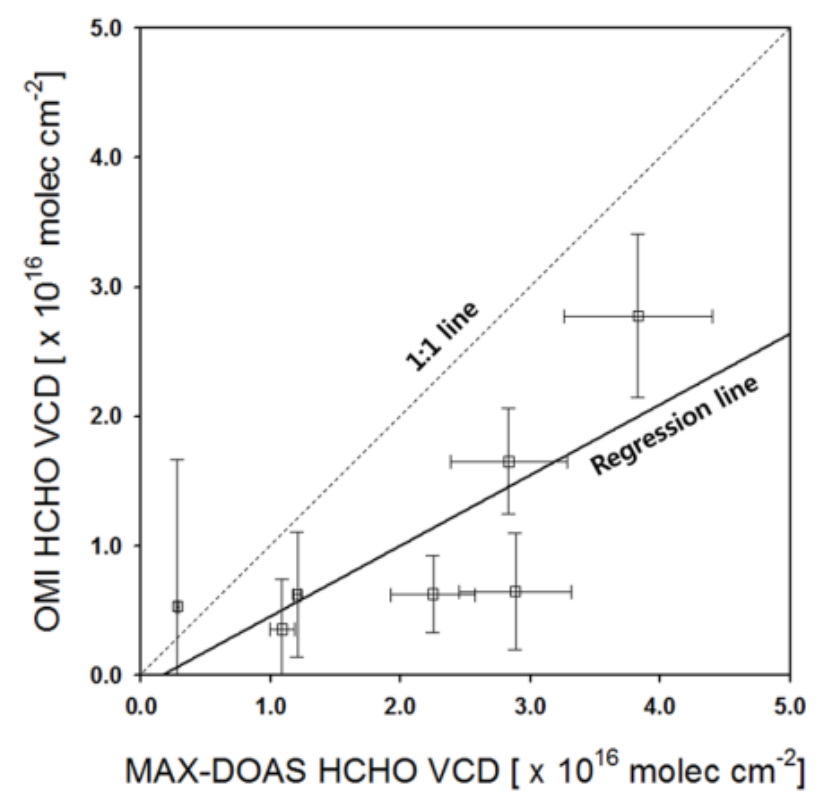

Figure 10. Correlations between $\mathrm{HCHO} \mathrm{VCDs}$ retrieved from the MAX-DOAS measurements and those obtained from OMI measurements during the CAREBEIJING campaign. The error bars (MAX-DOAS) represent the mean errors estimated from the retrieval covariance matrix whereas the error bars (OMI) represent the retrieval uncertainties

\section{Conclusions}

We investigated the diurnal characteristics of vertical HCHO profiles based on MAX-DOAS measurements in Beijing during the CAREBEIJING campaign for a one-month period over August and September 2006. In general, the highest HCHO VMR was found at the 0-1-km layer at 15:00 LT, implying that photo-oxidation of VOCs was most active near the surface at that time of day. In all retrieved profiles, the HCHO VMRs were found to decrease with altitude. No HCHO was detected in the 3-4-km layers during this measurement period. The mean HCHO VMRs were 3.54 (6.17), 1.06 (1.82), and 0.46 (0.80) ppbv for the 0-1, 1-2, and 2-3-km layers, respectively, at 09:00 (15:00) LT. In addition to investigating the diurnal characteristics of the vertical HCHO profiles, we compared the retrieved HCHO VCDs with those obtained from the OMI measurements. The HCHO VCDs obtained from the OMI measurements were smaller than those from the MAX-DOAS. This tendency might be associated with a weak sensitivity of the UV satellite sensor to HCHO, which is mostly present near the surface. 


\section{Acknowledgements}

This work was funded by the Korea Meteorological Administration Research and Development Program under Grant KMIPA 2015-6030.

\section{Author Contributions}

Hanlim Lee and Hitoshi Irie carried out the RTM simulations and $\mathrm{NO}_{2}$ VMR retrievals; Jaeyong Ryu and Seong-Ho Jang performed the spectral analyses. Junsung Park, Wonei Choi, and Hyunkee Hong carried out the MAX-DOAS measurements.

\section{Conflicts of Interest}

The authors declare no conflict of interest.

\section{References}

1. Nilsson, J.; Zheng, X.; Sundqvist, K.; Liu, Y.; Atzori, L.; Elfwing, A.; Arvidson, K.; Grafström, R. Toxicity of formaldehyde to human oral fibroblasts and epithelial cells: Influences of culture conditions and role of thiol status. J. Dent. Res. 1998, 77, 1896-1903.

2. De Smedt, I.; Stavrakou, T.; Müller, J.F.; van der A, R.; Van Roozendael, M. Trend detection in satellite observations of formaldehyde tropospheric columns. Geophys. Res. Lett. 2010, 37, L18808.

3. Dodge, M.C. Formaldehyde production in photochemical smog as predicted by three state-of-the-science chemical oxidant mechanisms. J. Geophys. Res-Atmos. (1984-2012) 1990, 95, 3635-3648.

4. Reis, S.; Friedrich, R. Emissions of ozone precursors. In Tropospheric Ozone Abatement; Springer: Berlin, Germany, 2000; pp. 25-33.

5. Heikes, B.; Snow, J.; Egli, P.; O’Sullivan, D.; Crawford, J.; Olson, J.; Chen, G.; Davis, D.; Blake, N.; Blake, D. Formaldehyde over the central pacific during PEM-Tropics B. J. Geophys. Res-Atmos. (1984-2012) 2001, 106, 32717-32731.

6. Shim, C.; Wang, Y.; Choi, Y.; Palmer, P.I.; Abbot, D.S.; Chance, K. Constraining global isoprene emissions with global ozone monitoring experiment (GOME) formaldehyde column measurements. J. Geophys. Res-Atmos. (1984-2012) 2005, 110, D24.

7. Singh, H.; Salas, L.; Chatfield, R.; Czech, E.; Fried, A.; Walega, J.; Evans, M.; Field, B.; Jacob, D.; Blake, D. Analysis of the atmospheric distribution, sources, and sinks of oxygenated volatile organic chemicals based on measurements over the pacific during TRACE-P. J. Geophys. Res-Atmos. (1984-2012) 2004, 109, D15.

8. Arlander, D.; Brüning, D.; Schmidt, U.; Ehhalt, D. The tropospheric distribution of formaldehyde during TROPOZ-II. J. Atmos. Chem. 1995, 22, 251-269.

9. Hak, C.; Pundt, I.; Trick, S.; Kern, C.; Platt, U.; Dommen, J.; Ordónez, C.; Prévôt, A.; Junkermann, W.; Astorga-Lloréns, C. Intercomparison of four different in-situ techniques for ambient formaldehyde measurements in urban air. Atmos. Chem. Phys. 2005, 5, 2881-2900. 
10. Junkermann, W.; Burger, J. A new portable instrument for continuous measurement of formaldehyde in ambient air. J. atmos. Oceanic Technol. 2006, 23, 38-45.

11. Lawson, D.; Biermann, H.; Tuazon, E.; Winer, A.; Mackay, G.; Schiff, H.; Kok, G.; Dasgupta, P.; Fung, K. Formaldehyde measurement methods evaluation and ambient concentrations during the carbonaceous species methods comparison study. Aerosol Sci. Tech. 1990, 12, 64-76.

12. Warneke, C.; Veres, P.; Holloway, J.; Stutz, J.; Tsai, C.; Alvarez, S.; Rappenglueck, B.; Fehsenfeld, F.; Graus, M.; Gilman, J. Airborne formaldehyde measurements using PTR-MS: Calibration, humidity dependence, intercomparison and initial results. Atmos. Meas. Tech. 2011, 4, 2345-2358.

13. Cardenas, L.; Brassington, D.; Allan, B.; Coe, H.; Alicke, B.; Platt, U.; Wilson, K.; Plane, J.; Penkett, S. Intercomparison of formaldehyde measurements in clean and polluted atmospheres. $J$. Atmos. Chem. 2000, 37, 53-80.

14. Fried, A.; Wert, B.P.; Walega, J.G.; Richter, D.A.; Potter, W.T. Airborne measurements of formaldehyde employing a high-performance tunable diode laser absorption system. In Proceedings of International Symposium on Optical Science and Technology, Seattle, WA, USA, 24 September 2002; pp. 177-183.

15. Jones, N.; Riedel, K.; Allan, W.; Wood, S.; Palmer, P.; Chance, K.; Notholt, J. Long-term tropospheric formaldehyde concentrations deduced from ground-based fourier transform solar infrared measurements. Atmos. Chem. Phys. 2009, 9, 7131-7142.

16. Vigouroux, C.; Hendrick, F.; Stavrakou, T.; Dils, B.; Smedt, I.D.; Hermans, C.; Merlaud, A.; Scolas, F.; Senten, C.; Vanhaelewyn, G. Ground-based FTIR and MAX-DOAS observations of formaldehyde at réunion island and comparisons with satellite and model data. Atmos. Chem. Phys. 2009, 9, 9523-9544.

17. Heckel, A.; Richter, A.; Tarsu, T.; Wittrock, F.; Hak, C.; Pundt, I.; Junkermann, W.; Burrows, J. MAX-DOAS measurements of formaldehyde in the Po-Valley. Atmos. Chem. Phys. 2005, 5, 909-918.

18. Pikelnaya, O.; Hurlock, S.C.; Trick, S.; Stutz, J. Intercomparison of multiaxis and long-path differential optical absorption spectroscopy measurements in the marine boundary layer. $J$. Geophys. Res-Atmos. (1984-2012) 2007, 112, D10.

19. Wittrock, F.; Richter, A.; Oetjen, H.; Burrows, J.P.; Kanakidou, M.; Myriokefalitakis, S.; Volkamer, R.; Beirle, S.; Platt, U.; Wagner, T. Simultaneous global observations of glyoxal and formaldehyde from space. Geophys. Res. Lett. 2006, 33, L16804.

20. Hönninger, G.; von Friedeburg, C.; Platt, U. Multi-axis differential optical absorption spectroscopy (MAX-DOAS). Atmos. Chem. Phys. 2004, 4, 231-254.

21. Fayt, C.; De Smedt, I.; Letocart, V.; Merlaud, A.; Pinardi, G.; Van Roozendael, M.; Roozendael, M. Qdoas Software User Manual; Belgian Institute for Space Aeronomy: Brussels, Belgium, 2011.

22. Vlemmix, T.; Hendrick, F.; Pinardi, G.; Smedt, I.D.; Fayt, C.; Hermans, C.; Piters, A.; Wang, P.; Levelt, P.; Roozendael, M.V. MAX-DOAS observations of aerosols, formaldehyde and nitrogen dioxide in the Beijing area: Comparison of two profile retrieval approaches. Atmos. Meas. Tech. 2015, 8, 941-963. 
23. Wagner, T.; Beirle, S.; Brauers, T.; Deutschmann, T.; Frieß, U.; Hak, C.; Halla, J.; Heue, K.; Junkermann, W.; Li, X. Inversion of tropospheric profiles of aerosol extinction and HCHO and $\mathrm{NO}_{2}$ mixing ratios from MAX-DOAS observations in Milano during the summer of 2003 and comparison with independent data sets. Atmos. Meas. Tech. 2011, 4, 2685-2715.

24. Lee, H.; Irie, H.; Gu, M.; Kim, J.; Hwang, J. Remote sensing of tropospheric aerosol using UV MAX-DOAS during hazy conditions in winter: Utilization of $\mathrm{O}_{4}$ absorption bands at wavelength intervals of 338-368 and 367-393 nm. Atmos. Environ. 2011, 45, 5760-5769.

25. Lee, H.; Ryu, J.; Kim, J.; Noh, Y.; Yoon, Y. Combined measurements of a UV mini MAX-DOAS system and a TX for retrieval of ambient trace gas mixing ratio: Comparisons with combined RTM and MAX-DOAS methods. Atmos. Environ. 2011, 45, 7218-7226.

26. Platt, U.; Stutz, J. Differential Absorption Spectroscopy; Springer: Berlin, Germany, 2008.

27. Kurucz, R.L.; Furenlid, I.; Brault, J.; Testerman, L. Solar Flux Atlas from 296 to $1300 \mathrm{~nm}$; National Solar Observatory Atlas: New Mexico, NM, USA, 1984.

28. Stutz, J.; Platt, U. Numerical analysis and estimation of the statistical error of differential optical absorption spectroscopy measurements with least-squares methods. Appl. Optics 1996, 35, 6041-6053.

29. Cantrell, C.A.; Davidson, J.A.; McDaniel, A.H.; Shetter, R.E.; Calvert, J.G. Temperature-dependent formaldehyde cross sections in the near-ultraviolet spectral region. J. Phys. Chem. 1990, 94, 3902-3908.

30. Chance, K. OMI algorithm theoretical basis document, volume IV: OMI trace gas algorithms. Accessed 2002, 12, 2009.

31. Chance, K.; Orphal, J. Revised ultraviolet absorption cross sections of $\mathrm{H}_{2} \mathrm{CO}$ for the HITRAN database, J. Quant. Spectrosc. Radiat. 2011, 112, 1509-1510.

32. Fish, D.; Jones, R. Rotational Raman scattering and the ring effect in zenith-sky spectra. Geophys. Res. Lett. 1995, 22, 811-814.

33. Kraus, S. DOASIS - A Framework Design for DOAS; Shaker: Herzogenrath, Germany, 2006.

34. Burrows, J.; Richter, A.; Dehn, A.; Deters, B.; Himmelmann, S.; Voigt, S.; Orphal, J. Atmospheric remote-sensing reference data from GOME-2. Temperature-dependent absorption cross sections of $\mathrm{O}_{3}$ in the 231-795nm range. J. Quant. Spectrosc. Radiat. Transf. 1999, 61, 509-517.

35. Hermans, C.; Vandaele, A.C.; Carleer, M.; Fally, S.; Colin, R.; Jenouvrier, A.; Coquart, B.; Mérienne, M.-F. Absorption cross-sections of atmospheric constituents: $\mathrm{NO}_{2}, \mathrm{O}_{2}$ and $\mathrm{H}_{2} \mathrm{O}$. Environ. Sci. Pollut. Res. 1999, 6, 151-158.

36. Vandaele, A.C.; Hermans, C.; Simon, P.C.; Carleer, M.; Colin, R.; Fally, S.; Merienne, M.-F.; Jenouvrier, A.; Coquart, B. Measurements of the $\mathrm{NO}_{2}$ absorption cross-section from $42,000 \mathrm{~cm}^{-1}$ to $10,000 \mathrm{~cm}^{-1}(238-1000 \mathrm{~nm})$ at $220 \mathrm{~K}$ and $294 \mathrm{~K}$. J. Quant. Spectrosc. Radiat. Transf. 1998, 59, 171-184.

37. Lee, H.; Irie, H.; Kim, Y.J.; Noh, Y.; Lee, C.; Kim, Y.; Chun, K.J. Retrieval of aerosol extinction in the lower troposphere based on UV MAX-DOAS measurements. Aerosol Sci. Tech. 2009, 43, 502-509.

38. Wagner, T.; Deutschmann, T.; Platt, U. Determination of aerosol properties from MAX-DOAS observations of the ring effect. Atmos. Meas. Tech. 2009, 2, 495-512. 
39. Clémer, K.; Van Roozendael, M.; Fayt, C.; Hendrick, F.; Hermans, C.; Pinardi, G.; Spurr, R.; Wang, P.; De Maziére, M. Multiple wavelength retrieval of tropospheric aerosol optical properties from MAXDOAS measurements in Beijing. Atmos. Meas. Tech. 2010, 3, 863-878.

40. Irie, H.; Nakayama, T.; Shimizu, A.; Yamazaki, A.; Nagai, T.; Uchiyama, A.; Zaizen, Y.; Kagamitani, S.; Matsumi, Y. Evaluation of MAX-DOAS aerosol retrievals by coincident observations using CRDS, lidar, and sky radiometer in Tsukuba, Japan. Atmos. Meas. Tech. 2015, 8, 1013-1054.

41. Irie, H.; Takashima, H.; Kanaya, Y.; Boersma, K.; Gast, L.; Wittrock, F.; Brunner, D.; Zhou, Y.; Roozendael, M.V. Eight-component retrievals from ground-based MAX-DOAS observations. Atmos. Meas. Tech. 2011, 4, 1027-1044.

42. Wagner, T.; Dix, B.; Friedeburg, C.v.; Frieß, U.; Sanghavi, S.; Sinreich, R.; Platt, U. MAX-DOAS $\mathrm{O}_{4}$ measurements: A new technique to derive information on atmospheric aerosols-principles and information content. J. Geophys. Res-Atmos. (1984-2012) 2004, 109, D22.

43. Rodgers, C.D. Inverse Methods for Atmospheric Sounding: Theory and Practice; World Scientific Singapore: Singapore, 2000.

44. Irie, H.; Kanaya, Y.; Akimoto, H.; Iwabuchi, H.; Shimizu, A.; Aoki, K. First retrieval of tropospheric aerosol profiles using MAX-DOAS and comparison with lidar and sky radiometer measurements. Atmos. Chem. Phys. 2008, 8, 341-350.

45. Frieß, U.; Monks, P. S.; Remedios, J. J.; Rozanov, A.; Sinreich, R.; Wagner, T.; Platt, U. MAX-DOAS O4 measurements: A new technique to derive information on atmospheric aerosols: 2. Modeling studies. J. Geophys. Res. 2006, 111, D14203, doi:10.1029/2005JD006618.

46. Palmer, P.I.; Jacob, D.J.; Chance, K.; Martin, R.V.; Spurr, R.J.; Kurosu, T.P.; Bey, I.; Yantosca, R.; Fiore, A.; Li, Q. Air mass factor formulation for spectroscopic measurements from satellites: Application to formaldehyde retrievals from the global ozone monitoring experiment. J. Geophys. Res-Atmos. (1984-2012) 2001, 106, 14539-14550.

(C) 2015 by the authors; licensee MDPI, Basel, Switzerland. This article is an open access article distributed under the terms and conditions of the Creative Commons Attribution license (http://creativecommons.org/licenses/by/4.0/). 